Winter 12-1-2008

\title{
Cervical Intramedullary Ganglioma
}

\author{
Harminder Singh MD \\ Thomas Jefferson University \\ Ashwini Sharan MD \\ Thomas Jefferson University \\ John K. Ratliff MD \\ Thomas Jefferson University
}

Follow this and additional works at: https://jdc.jefferson.edu/jhnj

Part of the Neurology Commons

Let us know how access to this document benefits you

\section{Recommended Citation}

Singh MD, Harminder; Sharan MD, Ashwini; and Ratliff MD, John K. (2008) "Cervical Intramedullary Ganglioma," JHN Journal: Vol. 4 : Iss. 2 , Article 3.

DOI: https://doi.org/10.29046/JHNJ.004.2.006

Available at: https://jdc.jefferson.edu/jhnj/vol4/iss2/3

This Article is brought to you for free and open access by the Jefferson Digital Commons. The Jefferson Digital Commons is a service of Thomas Jefferson University's Center for Teaching and Learning (CTL). The Commons is a showcase for Jefferson books and journals, peer-reviewed scholarly publications, unique historical collections from the University archives, and teaching tools. The Jefferson Digital Commons allows researchers and interested readers anywhere in the world to learn about and keep up to date with Jefferson scholarship. This article has been accepted for inclusion in JHN Journal by an authorized administrator of the Jefferson Digital Commons. For more information, please contact: JeffersonDigitalCommons@jefferson.edu. 


\section{Cervical Intramedullary Ganglioma}

\author{
Harminder Singh MD, Ashwini Sharan MD, John K. Ratliff MD \\ Department of Neurological Surgery, Thomas Jefferson University, Philadelphia, Pennsylvania
}

A 48 year male presented to the ER with severe headaches which were episodic in nature and which had been present for several weeks. Patient had a history of traumatic head injury (TBI) several years prior. Otherwise, he was in good health with no significant past medical or surgical history.

On physical exam, patient was oriented $\mathrm{x} 3$ with an intact cranial nerve exam. He had significant upper and lower extremity spasticity with mild hand intrinsic weakness. His motor exam was otherwise unremarkable. His gait was very spastic. He had sustained lower extremity clonus, upgoing toes, and increased tone in the upper and lower extremities. His sensation was intact to light touch, pinprick, proprioception and temperature.

\section{What imaging studies would you order?}

A CT scan of the brain was initially obtained secondary to the severity of the patients' headaches and past history of TBI.

The head CT revealed an old lacunar infarct in the left basal ganglia. There was no intracerebral hemorrhage or extra axial collection. However, in the spinal cord at the level of $\mathrm{C} 1$, an $8 \mathrm{~mm}$ hypodensity was noted.

This prompted an MRI of the cervicomedullary junction. An ovoid, 1.1 x 1.0 x $1.7 \mathrm{~cm}$ intramedullary lesion was seen expanding the cervical cord at the C1-2 level. It was hyperintense on T2-weighted images and hypointense on T1 weighted images, and demonstrated some mild curvilinear enhancement within the lesion.

\section{What is your differential diagnosis? Would you perform any further imaging?}

These radiographic findings were consistent with a low grade tumor such as an astrocytoma. An ependymoma or cord metastasis were considered less likely.

No evidence for primary malignancy was found on imaging of the chest, abdomen and pelvis.

Imaging of the entire neural-axis did not reveal any other lesions.

A CSF flow study on MRI was also performed to look at CSF flow dynamics, and evaluate for possible CSF outflow obstruction secondary to this lesion, which might have explained the patient's headaches. Unobstructed CSF flow was identified anterior and posterior to the cervicomedullary junction at the foramen magnum and at the level of the intramedullary lesion at C1-C2.

\section{How would you treat this lesion?}
A. Observation and close neurological follow up
B. Perform a lumbar puncture for CSF cytology
C. Radiation and/or chemotherapy
D. Excisional biopsy
E. Excisional biopsy followed by radiation and/or chemotherapy

This is a young, otherwise healthy male who is starting to develop neurological symptoms from a lesion with unknown pathology. Considering the rapid progression of his symptoms over a few weeks, we felt that it was necessary to expediently secure him a diagnosis via direct exploration of the lesion. Once the diagnosis was established, treatment tailored to his particular ailment could begin. While operative exploration of this lesion entails risk of significant morbidity, we felt the severity of his clinical findings and the progression of his deficit merited operative exploration.

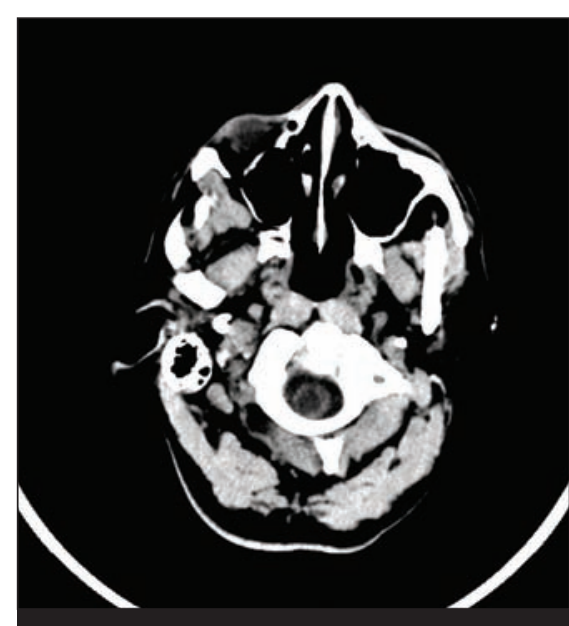

Figure 1

Pre-op axial non-contrast CT head showing hypodensity within the spinal cord

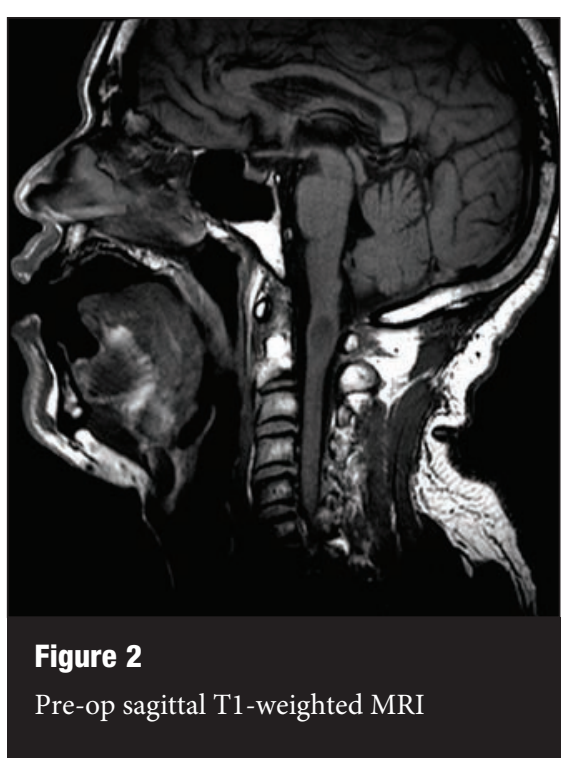

The diagnostic yield from CSF cytology is low $(\sim 26 \%)(3)$, although repeated sampling does increase the yield significantly. CSF flow cytometry also increases the diagnostic yield over CSF cytomorphology alone. (1) Newer techniques like fluorescence in situ hybridization (FISH) enhance the diagnostic yield for 


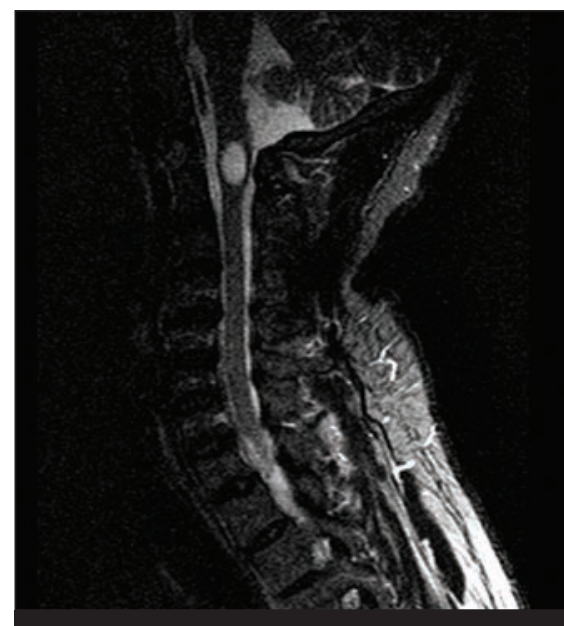

Figure 3

Pre-op sagittal T2-weighted MRI

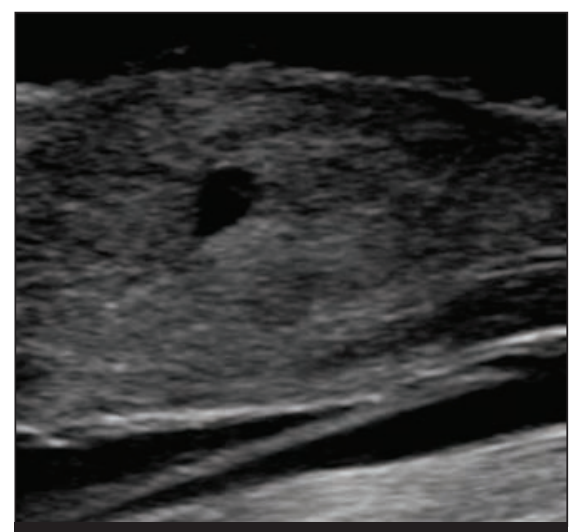

Figure 5

Intraoperative ultrasound image, pre resection

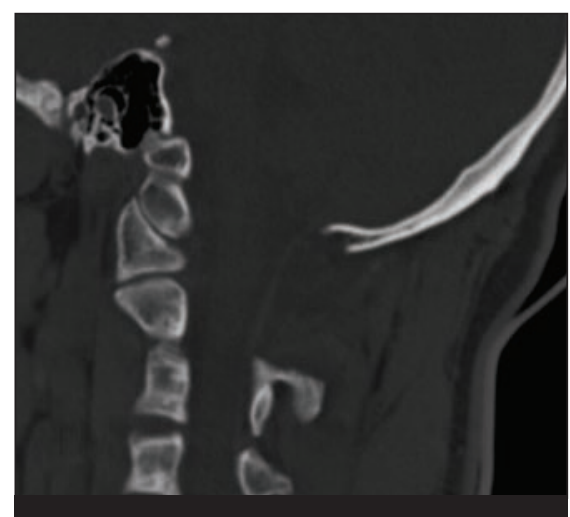

Figure 7

Post-operative sagittal CT

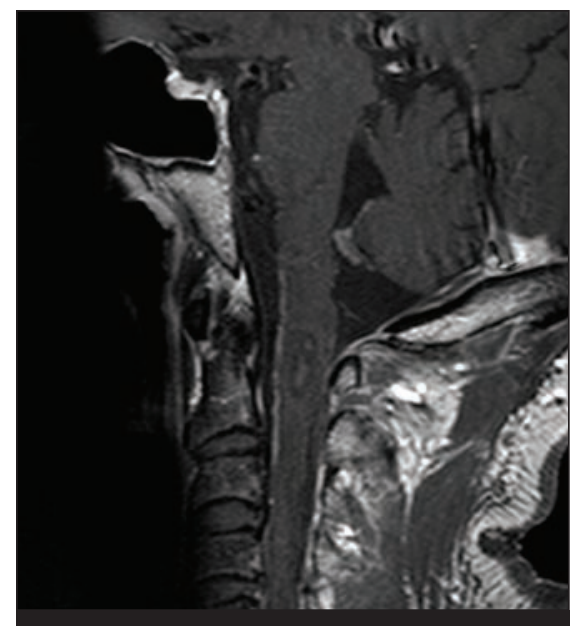

\section{Figure 4}

Pre-op sagittal post-gadolinium MRI
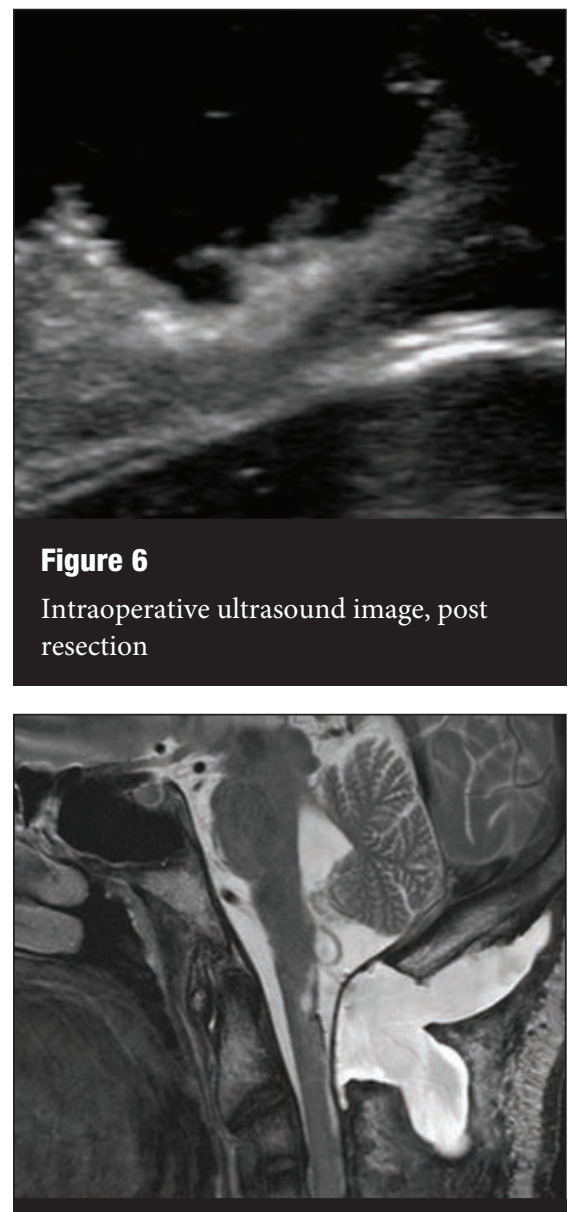

Figure 8

Post-operative sagittal MRI the detection of malignancy on the first lumbar puncture in patients clinically suspected of having leptomeningeal metastases (LMM). (10) Radiographic imaging did not demonstrate any leptomeningeal spread in our patient. In the absence of leptomeningeal spread, the chances of obtaining a diagnosis from CSF cytology are further diminished.

We decided to proceed with exploration and biopsy of the tumor. We planned to debulk the tumor and to possibly resect the entirety of the tumor predicated upon the lesion's histopathological findings at the time of frozen section and intraoperative behavior. Debulking the tumor would also alleviate the mass effect on the spinal cord, decrease tumor burden, and afford the patient a better chance at tumor control through adjuvant chemotherapy and radiation.

How would you counsel the patient regarding the surgical risks?

The risks and benefits of surgery were explained at length. It was emphasized to the patient that there was a substantial risk of neurologic worsening and a significant risk of paralysis secondary to the size of the tumor and its extremely sensitive location. The patient had previously suffered a significant head injury; hence, these discussions were also carried out with patient's mother who acted as his guardian. While the patient was felt to be thoroughly consentable, the patient's family was again counseled as to the severity of his diagnosis and the significant dangers of surgery.

\section{What surgical approach would you} use? What intra-operative tools would help you in localization of this lesion?

We decided to approach this lesion through a posterior cervical approach. The patient was positioned prone using the Mayfield three-pin headholder. The patient's neck was placed in gentle flexion to facilitate exposure of the occipitocervical junction. The posterior arch of $\mathrm{C} 1$, along with $50 \%$ of the top of the lamina of $\mathrm{C} 2$ was removed. At the base of the occiput, we performed a limited suboccipital craniectomy using the Midas-Rex drill.

The dura was opened next. Using intraoperative ultrasound localization, we identified the patient's large intramedullary tumor. We attempted to map the spinal cords' midline using SSEPs; however, due to poor recordings and extensive lateral spread, we were unable to adequately map the posterior elements.

We chose an entry point along the posterior elements. The spinal cord was entered via bipolar and creating a sharp incision in the 


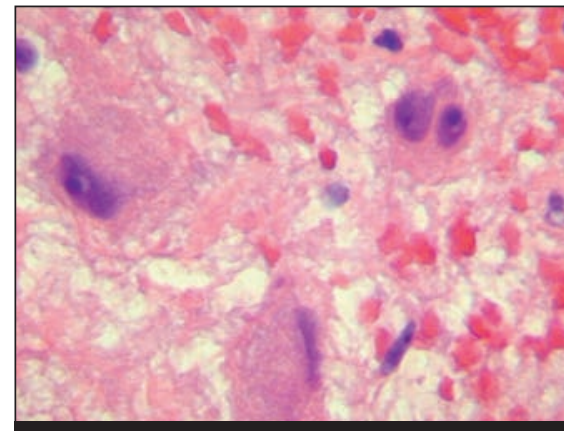

Figure 9

Atypical ganglion cells including binucleated ganglion cell

pia mater. The cord was opened further using microscissors. Using blunt dissection, we gently reflected the pia-arachnoid. Using pial sutures, we gently retracted the spinal cord bilaterally. The patient's intramedullary tumor was evident. Using blunt dissection, we gently developed a plane around the patient's intramedullary tumor. A biopsy was obtained and sent for frozen section. Frozen section returned a lowgrade astrocytoma.

We continued our resection, removing as much of the tumor as we felt safe. We periodically checked motor evoked potentials during our decompression. After we had completed our decompression, we used the ultrasound to confirm that no further gross elements of tumor were evident. There was a gliotic shell, which was evident around the spinal cord; however, based on ultrasound localization, the main portion of the patient's tumor had been successfully extirpated.

There was some mild loss of hand intrinsic motor evoked potentials during the procedure; however, this was less than $50 \%$ loss and was not felt to be severe. After hemostasis had been achieved, the wound was thoroughly irrigated. The dura was closed using \#6-0 Gore-Tex sutures.

Postoperatively, the patient recovered well. His motor and sensory exam remained stable.

Permanent section was consistent with that of ganglioglioma.

Ganglioglioma was first described by Courville in 1930 as a central nervous system neoplasm containing both astrocytic and neuronal components. Gangliogliomas are firm grayish tumors that may have cystic components. On light microscopy, atypicaldysplasticneurons, astrocytes, and

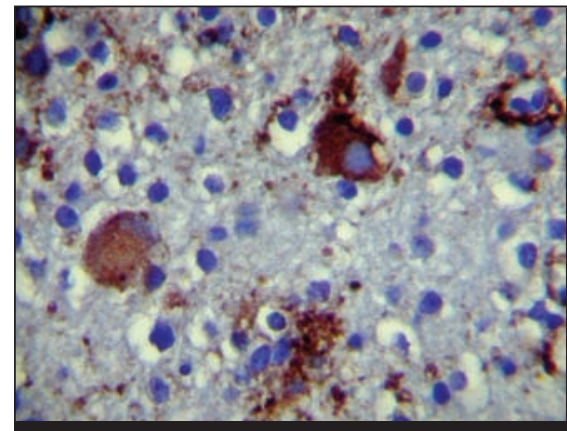

Figure 10

Chromogranin staining of atypical ganglion cells in background of neoplastic glial cells

fibrovascular stroma are observed. Infrequently, anaplastic degeneration occurs and involves the astrocytic component. Neoplastic ganglion cells are large and mature and reveal intense immunoreactivity with synaptophysin, show expression of the stem cell epitope CD34, and are often binucleated.

Most gangliogliomas are observed in the brain. Temporal lobes and cerebellar hemispheres are the most common locations. Rarely, they may also develop in the spinal cord. Only $1 \%$ of intramedullary spinal neoplasms are histologically gangliogliomas.

\section{Now that diagnosis has been established, would you recommend any further treatment for this patient?}

Radical surgery for intraspinal tumors can achieve long tumor-free survival without requiring adjuvant therapy.(4) In cases of lowgrade tumor, radical excision is associated with minimal morbidity and an excellent long-term prognosis when carried out before significant disability occurs.(2) Gangliogliomas are generally classified as WHO grade 1 lesions; however, malignant transformation can occur.

In one study, the 5-year actuarial survival rates for cerebral hemisphere, spinal cord, and brain-stem gangliogliomas were 93\%, $84 \%$, and $73 \%$, respectively $(p=0.7)$. The event-free survival rate at 5 years was $95 \%$ for cerebral hemisphere gangliogliomas and 36\% for spinal cord gangliogliomas ( $\mathrm{p}<0.05$ ); for brain-stem gangliogliomas the event-free survival rate at 3 years was $53 \%(\mathrm{p}<0.05)$. Multivariate analysis (Cox linear regression) revealed tumor location to be the only variable predictive of outcome, with spinal cord and brain-stem gangliogliomas having a 3.5- and 5-fold increased relative risk of recurrence, respectively, compared to cerebral hemisphere gangliogliomas. Histological grade was not predictive of outcome, although in each location there was a trend for higher-grade tumors to have a shorter time to recurrence.(6) It is concluded that radical surgery leads to longterm survival of patients with gangliogliomas, regardless of location, and adjuvant therapy can probably be reserved for special cases (e.g. tumors with a high KI 67 index). (4, 5, 7-9)

\section{References}

1. Bromberg JE, Breems DA, Kraan J, Bikker G, van der Holt B, Smitt PS, van den Bent MJ, van't Veer M, Gratama JW: CSF flow cytometry greatly improves diagnostic accuracy in CNS hematologic malignancies. Neurology 68:1674-1679, 2007

2. Epstein FJ, Farmer JP, Freed D: Adult intramedullary astrocytomas of the spinal cord. J Neurosurg 77:355-359, 1992.

3. Glass JP, Melamed M, Chernik NL, Posner JB: Malignant cells in cerebrospinal fluid (CSF): the meaning of a positive CSF cytology. Neurology 29:1369-1375, 1979.

4. Goh KY, Velasquez L, Epstein FJ: Pediatric intramedullary spinal cord tumors: is surgery alone enough? Pediatr Neurosurg 27:34-39, 1997.

5. Hamburger C, Buttner A, Weis S: Ganglioglioma of the spinal cord: report of two rare cases and review of the literature. Neurosurgery 41:1410-1415; discussion 14151416, 1997.

6. Lang FF, Epstein FJ, Ransohoff J, Allen JC, Wisoff J, Abbott IR, Miller DC: Central nervous system gangliogliomas. Part 2: Clinical outcome. J Neurosurg 79:867-873, 1993.

7. Miller DJ, McCutcheon IE: Hemangioblastomas and other uncommon intramedullary tumors. J Neurooncol 47:253270, 2000.

8. Park CK, Chung CK, Choe GY, Wang KC, Cho BK, Kim HJ: Intramedullary spinal cord ganglioglioma: a report of five cases. Acta Neurochir (Wien) 142:547-552, 2000.

9. Sawin PD, Theodore N, Rekate HL: Spinal cord ganglioglioma in a child with neurofibromatosis type 2. Case report and literature review. J Neurosurg 90:231-233, 1999.

10. van Oostenbrugge RJ, Hopman AH, Arends JW, Ramaekers FC, Twijnstra A: The value of interphase cytogenetics in cytology for the diagnosis of leptomeningeal metastases. Neurology 51:906-908, 1998. 